\title{
Erratum to: A Survey of the Hysteretic Duhem Model
}

\author{
Fayçal Ikhouane ${ }^{1}$
}

Published online: 8 August 2017

(c) CIMNE, Barcelona, Spain 2017

\section{Erratum to: Arch Computat Methods Eng} DOI 10.1007/s11831-017-9218-3

Proofing error was introduced at Page 38, Proposition 2 section and has been thus re corrected in original article.

Proposition 2 table has been corrected on original article.

Please add article "The original article was corrected."

The online version of the original article can be found under doi:10.1007/s11831-017-9218-3.

Fayçal Ikhouane

faycal.ikhouane@upc.edu

1 Department of Mathematics, Barcelona East School

of Engineering, Universitat Politècnica de Catalunya, carrer

Eduard Maristany, 16, 08019 Barcelona, Spain 